\title{
The Trellis Theory of Adult Online Learning
}

\author{
Betsy J. Bannier, Senior Member, IACSIT
}

\begin{abstract}
The purpose of this grounded theory study was to identify and explain factors that motivate and assist adult undergraduate students to both enroll and successfully complete an online course. Deepening our understanding of the motivation of adult, online students will assist faculty in more effectively meeting the needs of their students. Understanding the specific factors that motivate adult students to enroll in online, undergraduate courses will assist program directors in targeting their marketing and student recruitment efforts more effectively. The new understanding of adult students' motivation gleaned from this study is compared to existing motivation theories, specifically self-determination theory, goal theory, and expectancy-value theory. Similarities and differences are critically examined and a new trellis theory of online learning is presented.
\end{abstract}

Index Terms-Adult learning, goal setting, motivation, online learning.

\section{INTRODUCTION}

Motivation as a construct is both divergently defined and domain specific. In its most succinct presentation, motivation can be defined as an energizing force that guides behavior in the direction of a goal [1]. While a variety of motivational theories have been proposed, the three theories that are both highly interconnected and transferable to the academic motivation of adults are goal theory, self-determination theory, and expectancy-value theory.

Goal theory asserts that students' academic motivation is the self-influencing manifestation of attempts to achieve explicit, challenging goals [2], [3]. In the academic arena, students' behaviors are assumed to reflect their desires to achieve specific goals. Such goals may actually serve as a framework for sense-making and reacting to experiences, such as educational experiences. Students' overall reasons for participating in educational endeavors are often referred to as goal orientations, which are believed to serve as predictors of likely educational outcomes [4]. Goal theorists generally agree that more specific goals related to students' behavior occurring after they have made the decision to engage in the educational process can fall into one of four categories. Such goals are referred to as either learning goals, performance goals, social goals, or work avoidance goals [5].

In contrast, self-determination theory is based upon the tenet that an individual's perceived locus of behavioral causality depends upon whether the behavior is self-determined or controlled. Self-determined behavior is congruent with the perception of an internal locus of control, while behavior controlled by others is congruent with the

Manuscript received July 12, 2013; revised September 6, 2013.

B. Bannier is with Lake Region State College, Devils Lake, ND 58301 USA (e-mail: betsy.bannier@1rsc.edu). perception of an external locus of control [6]. While a learner may feel motivated by both self-determined and externally controlled behaviors, the regulatory processes employed by the learner will likely be quite different [7]. Self-determination theory asserts that learners are typically either extrinsically or intrinsically driven by needs for competency, relatedness, and autonomy to internalize the regulation of activities perceived as important, even when those activities are not particularly interesting [8].

A third motivational theory, expectancy-value theory, posits that learners are only likely to pursue goals and activities of which they believe they are capable, and of which they believe they understand the likely outcome of their efforts [9]. Expectancy-value theorists believe that learners make motivational decisions about the probability of achieving academic goals based upon both their level of expectation that personal goals are within their ability range and circumstances, and also upon the presumed value offered by achieving their goals

\section{Methodology}

\section{A. Research Questions}

Reference [10] describes the systematic design approach to grounded theory research which was employed to investigate the following research questions:

1) What intrinsic and extrinsic factors motivate adult, undergraduate students to enroll and persevere in successfully completing an online course?

2) What types of goals do adult, online undergraduate students set for themselves?

\section{B. Sampling}

Twelve adult learners, each of whom had completed an online, undergraduate chemistry course within the past two years, participated in this study. Each participant reported struggling with their chemistry course and yet persevered to complete the course successfully, earning a final grade of " $\mathrm{C}$ " or higher. Whether or not a potential study participant was classified as an "adult" was not determined by age, but by criteria agreed upon by adult learning experts [11]-[13]. Essentially, individuals who are adults fill adult social roles and are responsible for themselves. To that end, each study participant met one or more of the following characteristics: a) they were raising or have raised children, b) they were primary caregivers for a family member, c) they were financially independent of their parents, d) they were currently serving or had previously served in the military, or e) they were currently or had previously been married.

\section{Data Collection}

Data collection began with over 1,100 asynchronous 
discussion board postings completed by the study participants during their semester of online course enrollment, as well as transcripts from initial email interviews. In addition, each participant was asked to take photographs and participate in a follow-up telephone interview, following an established precedent for photography-guided interviewing and data collection [14], [15].

For this study, participants were given clear and simple guidelines to photograph a) their online workspace and symbols representing b) their motivators, c) their goals, and d) their experiences learning course content, using a provided single-use camera. Those photos served as catalysts for second, phone interviews, in which participants were asked to explain the significance of their captured images.

\section{Data Analysis}

All data, including participants' asynchronous discussion board postings, interview transcripts, and interpreted photographs, were coded according to a widely employed three-step process [10]. First, open coding was employed to create a variety of initial categories preliminarily related to the motivation and help seeking behaviors of adult, online students. Second, initial categories were grouped and several coded categories identified as axial codes were selected as key variables in answering my research questions. Third, data organized via open and axial coding was analyzed until central variables providing a theoretical underpinning of the motivation and help-seeking behaviors of adult, online students emerged. This step, referred to as "selective coding" is where theory was written to explain the connections revealed via axial coding.

\section{E. Quality Control}

Widely accepted qualitative research guidelines were used to gauge the trustworthiness of the inferences drawn from the data [16]-[18]. These guidelines include appropriateness, clarity, credibility, transferability, and significance. To that end, five questions were asked to assure quality control. First, were the approach and design effective and suitable for studying the motivation and help seeking behaviors of adult, online students? Second, were the purpose, approach, and design of the study clear to the reader? Third, were the results and conclusions of the study believable? Fourth, were the findings transferable to other, similar situations? Fifth, does the study make an important contribution? The answers to each of these questions were affirmative.

In addition to following the questions described above, peer review and member checks were incorporated into the quality control protocol. A peer familiar with qualitative research was asked to look for congruence (or incongruence) between the data, categories and codes. Participants themselves were also invited to review preliminary findings via e-mail attachments of written analyses, to help assure accurate interpretation of both interview responses and photographs.

\section{FINDINGS}

Two core variables, "transformative realization" and "situational standpoint", were extracted from the data, as shown in Fig. 1. Throughout this study, the data revealed that there are in fact two fundamental, core variables at play - one driving the realization of goals, and the other fueling academic motivation. Each of these variables is discussed below.

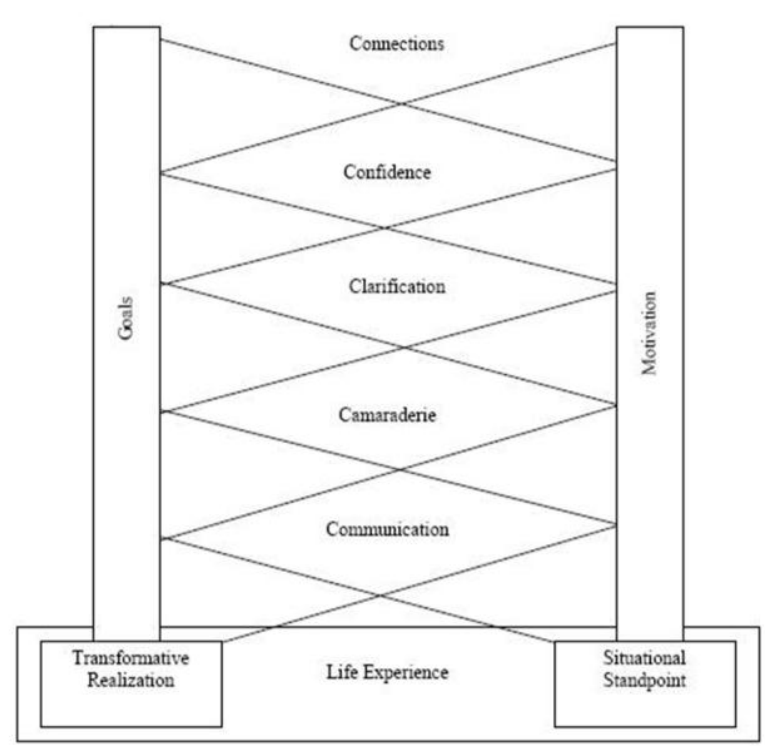

Fig. 1. Trellis theory of adult, online learning.

\section{A. Core Variables}

The grounded theory that emerged from this study is called the trellis theory of adult online learning. This theory explains the motivation and communication behaviors of adult learners in an online course from a growth standpoint rather than a deficit perspective. According to this trellis theory, core variables of "transformative realization" and "situational standpoint" are firmly rooted in a foundation of life experience, and serve as an individualized, supportive framework upon which adult, online learning takes place, metaphorically growing. A "transformative realization" is an awareness or understanding that leads to significant change. In the context of this trellis theory, the significant change is the emergence of an academic goal within an adult learner's life experience. In contrast to the well-known construct of disorienting dilemmas [19], a transformative realization needn't have a negative connotation. In fact, whether a transformative realization is negative or positive depends upon the standpoint of the person evaluating the realization.

The second core variable, "situational standpoint," is comprised of the set of life circumstances from which the motivation of adult learners emerges. Early in the data gathering process, the critical need to refrain from reliance on the oft-used word "barrier" [20] became clear. Overwhelmingly, participants did not speak of the specifics of their life situations, from single-parenting to military service, as obstructions. Such life situations colored the world view of participants, yes, but in focused rather than negative ways that nudged participants forward in the direction of their goals.

It is important to clarify that the use of the word "standpoint" is a deliberate nod to existing standpoint theories, which argue against dominant epistemology and propose that the standpoint of disadvantaged groups grants them ownership of knowledge often inaccessible or unavailable to dominant groups [21]. The trellis theory of 
adult online learning argues against the dominant presumption that the life situations of adult learners are somehow disadvantageous, and shows how the situational standpoint of adult learners fuels their motivation to succeed academically in their higher education endeavors.

\section{B. Growth Variables}

Together, the core variables of "transformative realization" and "situational standpoint" feed two growth variables, "goals" and "motivation." Goals are nurtured by and grow from the learners' transformative realizations, while motivation is nurtured by and grows from the learners' situational standpoint. Together, these core variables and their subsequent growth variables comprise the outer, primary structure within which adult learners enrolled in online courses build their overall learning experience.

The inner, lattice structure of the trellis theory is comprised of five modes of learner development: completing required communication, building camaraderie, seeking clarification, gaining confidence, and drawing connections. The overall relationship between the core variables, growth variables, and five modes of development is illustrated in Fig. 1.

\section{SUPPORTING DATA}

One participant, a woman we'll call Wanda with a fulfilling family life and fairly satisfying employment, spoke conversationally about her transformative realization that she really could go to college, explaining,

It was something that always hovered over me I even dreamed about it... My dreams haunted me, but I always felt I couldn't do it, couldn't do it. I got familiar with the teachers [at my place of employment], and they would say "You should go back to school to be a teacher, go back to school to be a teacher...you CAN be a teacher." I finally said, maybe...I went in to the [admissions] office, just to see what they had to say, and Bam! I was signed up and I was out the door and I was taking classes. So, it was a long process of pressure from peers and thinking about it...And I was signed up for college, and I walked out the door, and I was just shocked.

Wanda's transformative realization that she could pursue a degree in her 40s nurtured her goal of becoming an elementary school teacher, which she realized in precisely four years. Holding fast to her goal required sacrificing sleep, as she wanted her active children to recognize, "Hey, Mom did come to my game, but she's on the computer all night after that." It would be easy for an outside observer to view her parent-student balance as a negative entity, but Wanda didn't see it that way. In fact, motherhood framed her situational standpoint, nurturing her motivation to achieve her goal. Wanda referred to her children and explained,

I want to be able to give them attention, I want to be able to do things with them. You know, experience is knowledge and knowledge is wealth. I didn't have many experiences [with my working parents] as a child, and I want to give my children experiences, and I can't if I'm working all the time. I didn't want to do that to them. I had to go back to school.

Wanda's story revealed a time parallel between the transformative realization that shaped her goals, and the situational standpoint that nurtured her motivation. Her children were an integral part of her life experience when her transformative realization occurred, so her goals and motivation developed in tandem.

Another participant, Cassie, also revealed tandem development of goals and motivation, though from a very different, unfortunate life experience. Cassie explained,

I had a family loss of a brother to cancer, and he encouraged me to look at the nursing direction, which was not something that I had thought of. When he had been diagnosed it was available for me to travel to Texas and help care for him. After returning home from an extended stay my husband got ill and had a major surgery. Once diagnosed I cared for him for three months and he is doing well. My husband then said, "Please think about nursing, it really is possible," as he saw something I didn't. I then decided maybe I can.

Cassie's situational standpoint, specifically her husband's support in light of her caregiving experiences, began motivating her to realize her goal of a nursing degree from the onset of her transformative realization. As Cassie explained, "I never really liked school and couldn't believe I was accepted. I have enjoyed this education more than I could of [sic] imagined."

Not all participants reported an initial hesitation to pursue a college degree. Daniel's story illustrates in intriguing example of an adult learner who experienced a transformative realization in adolescence, carried his goal of pursuing higher education forward from adolescence, but lacked the situational standpoint to nudge him forward in the direction of his goal until a few years later. Daniel emphasized, "Ever since I graduated from high school I knew I wanted to have a degree in college." Despite his interest and conviction, Daniel took a significant detour on the path to his degree, enlisting in the Armed Forces. He stated rather flatly, "Four days after I graduated from high school, I was in Basic Training...I joined when I was 17 years old - I just completed 7 years in May."

The relationship between Daniel's goal and his indirect path is really not complicated, when one examines the transformative realization he experienced in adolescence. Daniel explained,

Money was very unstable. So there were things that I could not have as a child that I needed, like clothes and shoes, and I wanted to go to college when I graduated from high school. I didn't want to join the military, I wanted to go to college. But, I couldn't afford to go to college - my parents couldn't afford sending me to college, and I didn't want to graduate from college with fifty or sixty thousand dollars in debt.

Daniel aligned his elusive goal of a college degree with his military enlistment by taking on the challenge of enrolling in college classes between deployments, as his active duty commitments would allow. His motivation grew from a profound development in his situational standpoint. Having already explained his transformational realization, Daniel easily articulated the connection between his goal, his situational standpoint, and his motivation:

I'm going to be having a child come February... My long term goal is to become a radiologist and, by being a radiologist, I feel that I'll be more financially stable. For me, 
being financially stable is, being able to offer my children and my wife a stable life... so that when my kids do become older and decide that they want to go to college, they have that opportunity, so they don't have to join the military like I did.

\section{FIVE Modes of DEVELOPMENT}

While rooting one's academic motivation and goals in life experience was a simple, common finding, the creation of figurative "lattice" support structures depicted in Figure 1 and within these key variables was far more complex. Even so, a methodical process of open, axial, and selective coding [9] revealed how adult learners fairly consistently exhibit five modes of development within their online chemistry courses. These modes, described in detail below, are: completing required communication, building camaraderie, seeking clarification, gaining confidence, and drawing connections.

\section{A. Completing Required Communication}

All participants, while enrolled in online general chemistry, were required to complete weekly asynchronous "coffeeshop" discussion board postings as an integral component of the course. Minimum posting requirements generally included at least one fully explained solution to an assigned homework problem and at least two responses to classmates' postings. Participation points were awarded for these postings and compliance was high throughout the course, if a bit perfunctory at the beginning.

The majority of participants reported positive experiences with the coffeeshop discussion board, with some even preferring this mode of communication over traditional classroom discussions. As Wanda explained, "I would go straight to my classmates whom I felt comfortable asking questions. They didn't know me or who I was so I didn't care what I asked. There was no intimidation from a classroom full of classmates." One participant, Katherine, was less enthusiastic about her experiences communicating in the coffeeshop. She explained,

I like to hear someone's voice and converse in person versus online. It comes from a sense of not knowing whether I am being understood and a little bit of impatience. I know we were given the opportunity to contact by phone our instructor also-but I was often doing my homework late in the evening.

It stands to reason that completing required communication would serve as the first mode of development in an online course, followed closely by building camaraderie. Online participation is recognized as a dynamic process in which individuals learn by building and maintaining relationships (Hrastinski, 2009).

\section{B. Building Camaraderie}

Postings took on a tone of solidarity as project deadlines approached. For example, the week before students' water testing reports were due, Cassie posted,

Hello fellow chemists! My kitchen is now a lab and it's really interesting to put this product to work. My children always wanted a chemistry set and now [sic] they are all grown up they can't believe that I'm the one with the chemistry set... Good luck with the process.
In addition to personal disclosures, gratitude, and solidarity, participants injected plenty of humor into their online exchanges with classmates in their effort to build camaraderie. In one particularly long-running joke, Daniel consistently referred to a classmate as "Ricky Bobby." When asked to clarify this exchange in an interview, Daniel laughingly explained, “That was...Telladega Nights, it's a funny movie, and I believe we had a classmate named Ricky. I figured I'd put a little humor into the class." This was far from a flippant decision, as Daniel emphasized:

It's kind of hard to reveal a personality in online classes, 'cause you're just typing, and I'm not very well [sic] with transitioning words from my brain to my fingers. What I'm writing might not sound like what I'm thinking-it might sound like a third grader-but usually I try to make things a little more humorous because people tend to get along better like that. I try to do that at work as well.

\section{Seeking Clarification}

Only after participants both gained experience with required, asynchronous discussion board communication and also began to build camaraderie with classmates did participants demonstrate a willingness to admit areas of confusion and seek clarification. Many attempts at seeking clarification were broad and vague, as seen in Katherine's posting, "Help: can anyone help with the two problems from ch 6 [sic]. I have really struggled with the textbook problems." While Katherine admits confusion in this posting, she is nonspecific about the problems and/or concepts with which she needs assistance.

Targeted and specific clarification - seeking postings were less common. Despite repeated encouragement throughout the course, participants were generally reluctant to post incomplete or knowingly inaccurate solutions for feedback.

While study participants completed over 1,100 asynchronous discussion board postings in their respective online courses, postings aimed at clarification seeking in response to disagreement with a classmate's solution were exceedingly rare-seven total postings, to be precise. Wanda offered a rare example of this important form of clarification seeking, in response to a discussion about the chemical reaction responsible for the formation of rust. A classmate offered that rusting is a spontaneous process, to which Wanda replied,

I want to disagree with this but I'm not sure. This is why... definition of spontaneous reaction means ".... without any external influence." Wouldn't you say that rust is formed WITH external influences? Wouldn't the external influences be water and oxygen? Help me understand more if this is wrong.

Arguably the most challenging and exciting clarification seeking postings, from a transformational learning perspective, were those that dared to express discontent with the structure of the course content itself. Not surprisingly, these postings were typically authored by the same participants who also bravely posted their disagreement with classmates, such as Wanda. While frustrated with a particularly quantitative section of the course, Wanda posted,

If our major problem in Chemistry is solving the math problems and which formula we should use, isn't the focus of Intro to Chemistry being lost? The focus is now on the 
"Math" of Chemistry and not the "concept" of Chemistry. We have to create the basic understanding of the Chemistry before we are confident to start choosing the formulas we need to use for a problem.

These types of postings were actively encouraged via respectful, public responses, because the course instructor believed these postings held the potential to foster an environment of genuine co-learning. Alas, these particular clarification - seeking postings were rare.

\section{Gaining Confidence, Drawing Connections}

The constructs of gaining confidence and drawing connections are presented together because these two, upper level developmental modes are closely interrelated. Participants who demonstrated high levels of confidence as the course progressed were also more likely to demonstrate an understanding of tangible connections between their chemistry course and other disciplines. For instance, Cassie stood out in her ability to draw connections, bringing such real world topics into her asynchronous discussion board postings as her story about a friend who received hyperbaric therapy after an accident, her experience learning of fuel shortages in the Dominican Republic while traveling, and her understanding of the politics surrounding a proposed ethanol plant near her hometown. The class discussions sparked by Cassie's stories were highly relevant in that they were closely related to current course topics (gas laws, thermodynamics, alternative fuels). Not surprisingly, Cassie's explanation of her attitude toward learning online course content reflected a high level of confidence:

I felt I had good skills. I really wanted to get through this class and get out of it as much as possible. This area of learning is really important for the degree I am in and when you enter these classes, the expense is costly and a person needs to learn as much in life as possible.

Similarly, Jacqueline conveyed both a well-developed sense of confidence related to studying general chemistry and a clear ability to identify connections. She stated enthusiastically that, even if general chemistry was not a required component of her degree program, she "would have enrolled because I love chemistry and the sciences." Later, she displayed the same enthusiasm when she explained,

I was definitely able to see connections between [the course] and my future career goals. My goal is to be a doctor and the physiological processes of the body have everything to do with chemistry, so it's hard not to see a connection.

Participants who expressed somewhat less confidence in their experience learning chemistry tended to find only vague, general connections between course concepts and other disciplines. For example, while Pam did not outwardly report a lack of confidence, she didn't exactly exude confidence, either. "I just wished for it to be over! I knew I needed to have the chemistry credit so I had no intention of dropping out," was her most positive mindset. When asked if she could explain any connections between chemistry and other fields, she replied,

Everything is related...I think it is all connected. I may not see a connection right now for all of it but as the year progresses I know that I will make those connections as I have already seen some. With the nursing classes, it makes it all come together.
Pam's response does not reflect an understanding of concrete connections, but her response at least reflects an understanding that connections do exist, even if she isn't clear as to exactly what those connections may be. Similarly, Rich struggled in his sincere attempt to articulate connections between his online course and real life beyond the course. While he initially stated, "I did see the relation behind the soil and water labs to my everyday life," he later admitted that "I know in my career path that I will probably never run into chemistry again so it all seemed irrelevant."

Not surprisingly, the participant with the least outward confidence learning online course content also reported a complete lack of seeing connections. For example, Alisa lacked confidence to the point of admitting to feeling as though she wanted to drop her online course "every time I was frustrated with it. It was not my favorite thing to do just because it was confusing for me. I had to complete it for my degree." In response to being asked if she saw connections between chemistry and other fields, Alisa unsteadily replied, "I thought that if I were to go deep into nursing I would have the connection." When asked to clarify this statement, Alisa took a breath and admitted, "I have really never seen the need for chemistry - sorry!"

\section{DISCUSSION AND CONCLUSIONS}

The trellis theory of adult online learning offers a framework for understanding goals and academic motivation within the context of the whole learner. The trellis isn't the story in and of itself; rather, it supports the complexity of the adult learning experience in an online environment. Put another way, it would not make sense to embrace the theory without the learner any more than it would make sense to place a trellis in a garden without a plant.

This theory differs from existing motivational theories in several important ways. First, the trellis theory of online learning asserts that the motivation and goals of adult learners cannot be fully understood without first examining the situational standpoints and transformational experiences that arise from learners' life experiences. Indeed, the motivation and goals of adult learners are as organic as the learners themselves; the manifestation of individual constructs including self-efficacy, autonomy, and persistence, as they relate to academic goals and motivation, grow from learners' lived experiences and perspectives.

Second, the trellis theory proposes that standpoint can be and indeed is individually asserted. Current literature acknowledges the multiplicity of standpoints, along with the privileged, well - researched standpoints of individuals including those self-identifying as feminists, lesbians, African-Americans, and Latinas. A natural progression of this line of theory would be to acknowledge the privileged standpoints of single mothers, farmers, military members, et cetera. To argue against this idea would be to suggest that the standpoints of some individuals are more privileged or more worthy of acknowledgement in the academy than others; this is an idea that the researcher philosophically rejects.

Third, the trellis theory heeds the suggestions made by adult educators that adult motivation is complex and difficult to observe directly [22], [23]. This is particularly true in 
asynchronous discussion board communication formats [24]. To that end, the trellis theory takes an important step away from ranking or otherwise critiquing the types of goals and motivation that adult learners possess. The trellis theory of online learning accepts without judgment that notion that learners' goals, whether they are learning goals, performance goals, or some other form of goals, are often rooted in transformational life experiences, and proposes that only the learner is privileged to critique that connection. Similarly, the trellis theory accepts without judgment the notion that learners' motivation, whether extrinsic or intrinsic, is rooted in their unique situational standpoint, which an outside observer is not privileged to critique.

\section{REFERENCES}

[1] T. Karsenti and G. Thibert, "What type of motivation is truly related to school achievement? A look at 1428 high-school students," presented at the AERA Annual Meeting, San Francisco, CA, April 1995.

[2] A. Bandura, "Perceived self-efficacy in cognitive development and functioning," Educational Psychologist, vol. 28, no. 2, pp. 117-148, 1993.

[3] T. Seifert, "Understanding student motivation," Educational Research, vol. 46, no. 2, pp. 137-149, 2004.

[4] E. Anderman, C. Austin, and D. Johnson, "The Development of Goal Orientation," in Development of Achievement Motivation, A. Wigfield and J. Eccles, Eds., San Diego, CA: Academic Press, 2002, pp. 197-220.

[5] T. Seifert and B. O'Keefe, "The relationship of work avoidance and learning goals to perceived competence, externality and meaning," British Journal of Educational Psychology, vol. 71, pp. 81-92, 2001.

[6] E. Deci and R. Ryan, "Self-Determination Theory," in Handbook of Theories of Social Psychology, P. Van Lange, A. Kruglanski, and E. Higgins, Eds., Thousand Oaks, CA: Sage, 2011, vol. 1, pp. 416-433.

[7] P. Pintrich and T. Garcia, "Self-Regulated Learning in College Students: Knowledge, Strategies, and Motivation," in Student Motivation, Cognition, and Learning; Essays in Honor of William J. McKeachie, P. Pintrich, D. Brown, and C. Weinstein, Eds., Hillsdale, NJ: Lawrence Erlbaum Associates, 1994, pp. 113-130.

[8] M. Covington and E. Dray, "The Developmental Course of Achievement Motivation: A Need-Based Approach," in Development of Achievement Motivation, A. Wigfield and J. Eccles, Eds., San Diego, CA: Academic Press, 2002, pp. 33-56.

[9] A. Wigfield, S. Tonks, and S. Klauda, "Expectancy-Value Theory," in Handbook of Motivation at School, K. Wentzel and A. Wigfield, Eds., Charlottesville, VA: Routledge, 2009, pp. 55-75.

[10] A. Strauss and J. Corbin, Basics of Qualitative Research: Techniques and Procedures for Developing Grounded Theory, $2^{\text {nd }}$ ed. Newbury Park, CA: Sage, 1998.

[11] M. Knowles, The Modern Practice of Adult Education: From Pedagogy to Andragogy, Chicago, IL: Follet Publishing Company, 1980.
[12] S. Merriam, "Andragogy and Self-Directed Learning: Pillars of Adult Learning Theory," in The New Update on Adult Learning Theory. New Directions for Adult and Continuing Education, S. Merriam, Ed., San Francisco, CA: Jossey-Bass, 2001, pp. 3-14.

[13] R. Wlodkowski, Enhancing Adult Motivation to Learn, Revised ed., San Francisco, CA: Jossey-Bass, 1999.

[14] W. Fox-Turnbull, "Stimulated Recall Using Autophotography-A Method for Investigating Technology Education," in Proc. PATT-2 Conf., Delft, The Netherlands, 2009, pp. 204-217.

[15] E. Taylor, "Using still photography in making meaning of adult educators' teaching beliefs," Studies in the Education of Adults, vol. 34, no. 2, pp. 123-140, 2002

[16] Y. Lincoln and E. Guba, Naturalistic Inquiry, Newbury Park, CA: Sage, 1985.

[17] J. Goetz and M. LeCompte, Ethnography in Qualitative Design in Educational Research, New York, NY: Academic Press, 1984.

[18] F. Erickson, "Qualitative Methods in Research on Teaching," in Handbook of Research on Teaching, $3^{\text {rd }}$ ed., M. Wittrock, Ed., New York, NY: Macmillan, 1986, pp. 119-161.

[19] J. Mezirow, Transformative Dimensions of Adult Learning, San Francisco, CA: Jossey-Bass, 1991.

[20] K. Cross, Adults as Learners, San Francisco, CA: Jossey-Bass, 1981.

[21] J. Wood, "Feminist standpoint theory and muted group theory: Commonalities and divergences," Women and Language, vol. 28, no. 2, pp. 61-65, 2005.

[22] S. Hrastinski, "A theory of online learning as online participation," Computers \& Education, vol. 52, no. 1, pp. 78-82, 2009.

[23] M. Ponton, M. Derrick, and P. Carr, "The relationship between resourcefulness and persistence in adult autonomous learning," Adult Education Quarterly, vol. 55, no. 2, pp. 116-128, 2005.

[24] M. Andresen, "Asynchronous discussion forums: Success factors, outcomes, assessments, and limitations," Educational Technology \& Society, vol. 12, no. 1, pp. 249-257, 2009.

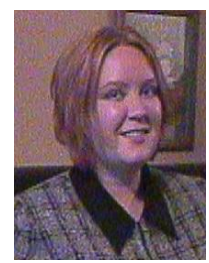

Betsy J. Bannier earned her $\mathrm{Ph} . \mathrm{D}$. in adult \& continuing education with an emphasis in online chemistry education at University of Wisconsin Milwaukee (USA) in 2009. She earned her M.S. in analytical chemistry with a cognate in chemical education at University of North Dakota (Grand Forks, ND USA) in 2000, and her B.A. in mathematics and chemistry at Alverno College (Milwaukee, WI USA) in 1997

She is an assistant professor of Chemistry and Mathematics Online at Lake Region State College in Devils Lake, North Dakota. She has 15 years of experience teaching in higher education, primarily in the field of undergraduate, online laboratory chemistry. In her current position, she serves as both an online Master Course developer and a mentor for new online faculty. Her work has been published in a variety of journals including Journal of Science Education and Technology, Journal of Developmental Education, and Radical Teacher. Her current research interests include the motivation of adult online students and the applications of concept mapping in online learning environments. 